ARTICLE

https://doi.org/10.1038/s41467-019-08580-9

\title{
Low temperature self-densification of high strength bulk hexagonal boron nitride
}

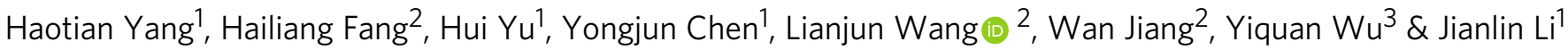

Hexagonal boron nitride (hBN) ceramics are expected to have wide applications at high temperatures as both a structural and functional material. However, because of its flake structure and general inertness, it is currently impossible to sinter hBN powder to a dense bulk (with a relative density of above $96 \%$ ) even at $2000^{\circ} \mathrm{C}$. Here, we report dense bulk hBN with $97.6 \%$ theoretical density achieved at a lower preparation temperature $\left(1700^{\circ} \mathrm{C}\right)$ via a self-densifying mechanism without sintering additives. During the sintering process, cubic boron nitride particles incorporated into the $\mathrm{hBN}$ flake powders transform into $\mathrm{BN}$ onions with a significant volume increase, thus filling in voids among the $\mathrm{hBN}$ flakes and highly densifying the hBN bulks. The resulting dense hBN ceramics possess 2-3 times the strength of traditional hBN ceramics. This phase-transition-induced volume expansion strategy could lead to dense sintered compacts with high performance in other ceramic systems.

\footnotetext{
${ }^{1}$ State Key Laboratory of Marine Resource Utilization in South China Sea \& School of Materials and Chemical Engineering, Hainan University, No. 58 Renmin Ave, Haikou 570228, China. ${ }^{2}$ State Key Laboratory for Modification of Chemical Fibers and Polymer Materials \& College of Materials Science and Engineering, Donghua University, Shanghai 201620, China. ${ }^{3}$ Kazuo Inamori School of Engineering, New York State College of Ceramics, Alfred University, 2 Pine Street, Alfred, NY 14802-1296, USA. Correspondence and requests for materials should be addressed to L.W. (email: wanglj@dhu.edu.cn) or to Y.W. (email: wuy@alfred.edu) or to J.L. (email: jlli@hainu.edu.cn)
} 
exagonal boron nitride (hBN) ceramics are widely-used materials with excellent properties, characterized by its excellent refractory behaviour at high-temperatures, chemical inertness, high lubricity, excellent thermal shock resistance, and favourable dielectric properties ${ }^{1-4}$. hBN ceramics exhibit high thermal conductivity $\left(130-150 \mathrm{~W} \mathrm{~m}^{-1} \mathrm{~K}^{-1}\right.$ parallel to the plane and $22-25 \mathrm{~W} \mathrm{~m}^{-1} \mathrm{~K}^{-1}$ in the perpendicular direction $)^{5}$, a low dielectric constant (4.0-5.4) and a low dielectric loss tangent $\left(3 \times 10^{-4}\right)^{1}$. However, the generally low density and weak mechanical strengths attainable by current consolidation techniques reduce the applicability of the material. As such, the main challenge with $\mathrm{hBN}$ ceramics is to improve the density of $\mathrm{hBN}$ ceramics, which seems a challenging task to overcome using conventional consolidation practices.

hBN has a typical layered structure similar to graphite, with an equal number of alternating $\mathrm{B}$ and $\mathrm{N}$ atoms that are covalently bonded by $\mathrm{sp}^{2}$ hybridization within a two-dimensional layer. However, the material also exhibits remarkable ionic character ${ }^{6}$, resulting in electrons in the $\pi$ bond that cannot be delocalized. As such, $\mathrm{hBN}$ is not a conductor like graphite, where the $2 \mathrm{D}$ layers are held together by weak van der Waals forces ${ }^{7}$, which also allows the layers to easily slide over each other. The special layered structure of hBN makes it difficult for the hBN flakes to stack densely and the strong in-layer covalent bonding results in the sluggish self-diffusion during sintering. All these hinder the densification of the $\mathrm{hBN}$ ceramics. Conventional pressureless sintering of $\mathrm{hBN}$ powder without any additives results in ceramics of less than $70 \%$ relative density ${ }^{8-10}$. Therefore, hot-pressing (HP) is typically adopted to prepare dense hBN ceramics, although sintering additives are still required to achieve suitable densities.

A variety of sintering additives have been explored to promote the densification of boron nitride ceramics, including $\mathrm{B}_{2} \mathrm{O}_{3}$ and a number of other oxides (Table 1). Although the addition of $\mathrm{B}_{2} \mathrm{O}_{3}$ does promote densification by providing a low melting liquid that enhances diffusion during sintering, the residual $\mathrm{B}_{2} \mathrm{O}_{3}$ is detrimental to the material's resistance to water attack and its high temperature properties. Other oxide additives are used that react with the $\mathrm{B}_{2} \mathrm{O}_{3}$ on the hBN flake surface to form an oxide glass liquid that facilitates consolidation. When a significant amount of these additives are used, they also act as reinforcements to enhance the materials' mechanical properties, as summarized in Table 1.

Although oxide additives are beneficial in achieving higher densities and better mechanical properties in hBN ceramics, their addition significantly harms the dielectric and thermal properties of the material. hBN ceramics produced with sintering aids cannot be used at extremely high temperatures, and their resistance to chemical attack is greatly reduced. As such, the addition of sintering additives eliminates the favourable properties that make boron nitride a unique and attractive material in the first place.

Recently, Zhang et al. ${ }^{11}$ sintered hBN without any additives via spark plasma sintering (SPS) under an applied pressure of 100 $\mathrm{MPa}$ and achieved a relative density of $95.1 \%$ at a temperature of $2000^{\circ} \mathrm{C}$. While Zhang's results are encouraging, the sintering conditions are too harsh to be feasible for the mass production of dense, high-purity dense hBN ceramics. Additionally, while the achieved density is an improvement on past results, significant room for improvement still exists.

All previous studies seemingly indicated that the upper limit of the relative density of $\mathrm{hBN}$ ceramics is approximately $95 \%$ and that the preparation of dense, additive-free hBN ceramics is all but an insoluble problem, still, efforts have been made. In our recent research ${ }^{12}$, we sintered diamond powders at $1600{ }^{\circ} \mathrm{C}$ by SPS and obtained graphite onion bulks with superior strength. These graphite onions were derived from nano-diamond particles. This achievement has made us draw upon an alternative route to synthesize high strength hBN (HSHBN) bulk materials using $\mathrm{BN}$ onions produced in situ from cubic boron nitride $(\mathrm{cBN})$ as sintering aids and reinforcements.

$\mathrm{cBN}$, a polymorph of hBN, has very similar crystal structure and lattice constant as diamond and transforms to $\mathrm{hBN}$ at approximately $1400^{\circ} \mathrm{C}$ under ambient pressure conditions (more information in Supplementary Note 1$)^{13-15}$. When heated to a high temperature above $1400^{\circ} \mathrm{C}, \mathrm{cBN}$ particles gradually transform into a structure of the $\mathrm{BN}$ concentric-shell onion morphology ${ }^{16}$.

Herein, we report the preparation of pure, dense and high strength $\mathrm{hBN}$ ceramics through the sintering of $\mathrm{cBN} / \mathrm{hBN}$ powder mixtures via SPS (Fig. 1, Table 2). As cBN has a significantly higher density $\left(3.48 \mathrm{~g} \mathrm{~cm}^{-3}\right)$ than $\mathrm{hBN}\left(2.27 \mathrm{~g} \mathrm{~cm}^{-3}\right)$, the transformation of $\mathrm{cBN}$ particles to $\mathrm{BN}$ onions during sintering is accompanied by a significant volumetric expansion. The expanding material serves to both fill the voids between larger $\mathrm{hBN}$ particles, and subsequently reduce diffusion distances and allows it to assist in the densification process. With this method, we achieve low-temperature sintering of high density and high strength BN bulk materials without any additives. The strategy is efficient and opens up new possibilities for applications in many other material systems.

\section{Results}

Microstructure. The X-ray diffraction (XRD) patterns of the raw materials used in this study and the sintered HSHBN bulks with $0-100 \mathrm{wt} \% \mathrm{cBN}$ sintered at $1700^{\circ} \mathrm{C}$ for $5 \mathrm{~min}$ are shown in Fig. 2a. Six diffraction peaks detected are apparent in the XRD pattern of HSHBN samples at $26.63^{\circ}, 41.51^{\circ}, 43.75^{\circ}, 50.00^{\circ}, 54.85^{\circ}$ and $75.73^{\circ} 2 \theta$, correspond to the (002), (100), (101), (102), (004) and (110) reflections of $\mathrm{hBN}$, respectively ${ }^{17}$. No diffraction peaks corresponding to $\mathrm{cBN}$, located at $43^{\circ}, 50^{\circ}$ and $74^{\circ} 2 \theta$, can be detected, indicating that all of the starting $\mathrm{cBN}$ has transformed to hBN during sintering.

During conventional uniaxial hot pressing of common hBN, the hBN flakes become preferentially oriented because of the flake structure of the hBN particles, which produces pronounced anisotropy in end ceramics ${ }^{5}$. This preferred orientation can be substantiated by XRD analysis. The anisotropy of hBN ceramics is apparent in its strong (002) reflection (Fig. 2a), which declines

Table 1 hBN ceramics with different additives

\begin{tabular}{llll} 
Additive(s) & Processing & Relative density & Side effect \\
\hline $4 \mathrm{wt} \% \mathrm{~B}_{2} \mathrm{O}_{3}^{2}$ & $\mathrm{HP}$ & Water-resistance and high-temperature refractoriness reduced \\
$4.5 \mathrm{wt} \% \mathrm{~B}_{2} \mathrm{O}_{3}{ }^{32}$ & $\mathrm{SPS}, 1600^{\circ} \mathrm{C}, 25 \mathrm{MPa}$ & $94.7 \%$ & \\
$5 \mathrm{wt} \% \mathrm{Al}_{2} \mathrm{O}_{3} / \mathrm{CaO}^{33}$ & $\mathrm{HP}, 1800^{\circ} \mathrm{C}, 40 \mathrm{MPa}$ & $94.1 \%$ & High-temperature refractoriness reduces and dielectric loss increased \\
$20 \mathrm{wt} \% \mathrm{mullite}^{7,34}$ & $\mathrm{HP}, 1900^{\circ} \mathrm{C}, 30 \mathrm{MPa}$ & $94 \%$ & \\
$22 \mathrm{wt} \% \mathrm{Y}_{2} \mathrm{Si}_{2} \mathrm{O}_{7} 35$ & $\mathrm{HP}, 1740^{\circ} \mathrm{C}, 25 \mathrm{MPa}$ & $85 \%$ & \\
$\mathrm{None}^{11}$ & $\mathrm{SPS}, 2000^{\circ} \mathrm{C}, 100 \mathrm{MPa}$ & $95.1 \%$ & None \\
\hline
\end{tabular}




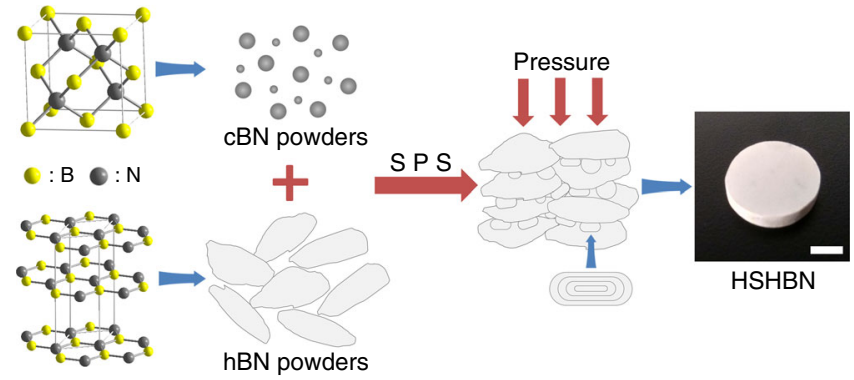

Fig. 1 Schematic illustration of the HSHBN consolidation process. The scale bar represents $5 \mathrm{~mm}$

\begin{tabular}{|llll|}
\hline \multicolumn{3}{|l|}{ Table 2 A list of the examined compositions } \\
$\begin{array}{l}\text { Sample } \\
\text { code }\end{array}$ & $\begin{array}{l}\text { wt\% cBN } \\
\text { powders (200 } \\
\text { nm) }\end{array}$ & $\begin{array}{l}\text { wt\% cBN } \\
\text { powders (400 } \\
\text { nm) }\end{array}$ & $\begin{array}{l}\text { wt\% hBN } \\
\text { powders (1-2 } \\
\boldsymbol{\mu m})\end{array}$ \\
\hline hBN & 0 & 0 & 100.00 \\
ceramics & & 11.25 & 85.00 \\
HSHBN-15 & 3.75 & 22.50 & 70.00 \\
HSHBN-30 & 7.50 & 37.50 & 50.00 \\
HSHBN-50 & 12.50 & 60.00 & 20.00 \\
HSHBN-80 & 20.00 & 70.00 & 0 \\
HSHBN-100 & 30.00 & & \\
\hline
\end{tabular}
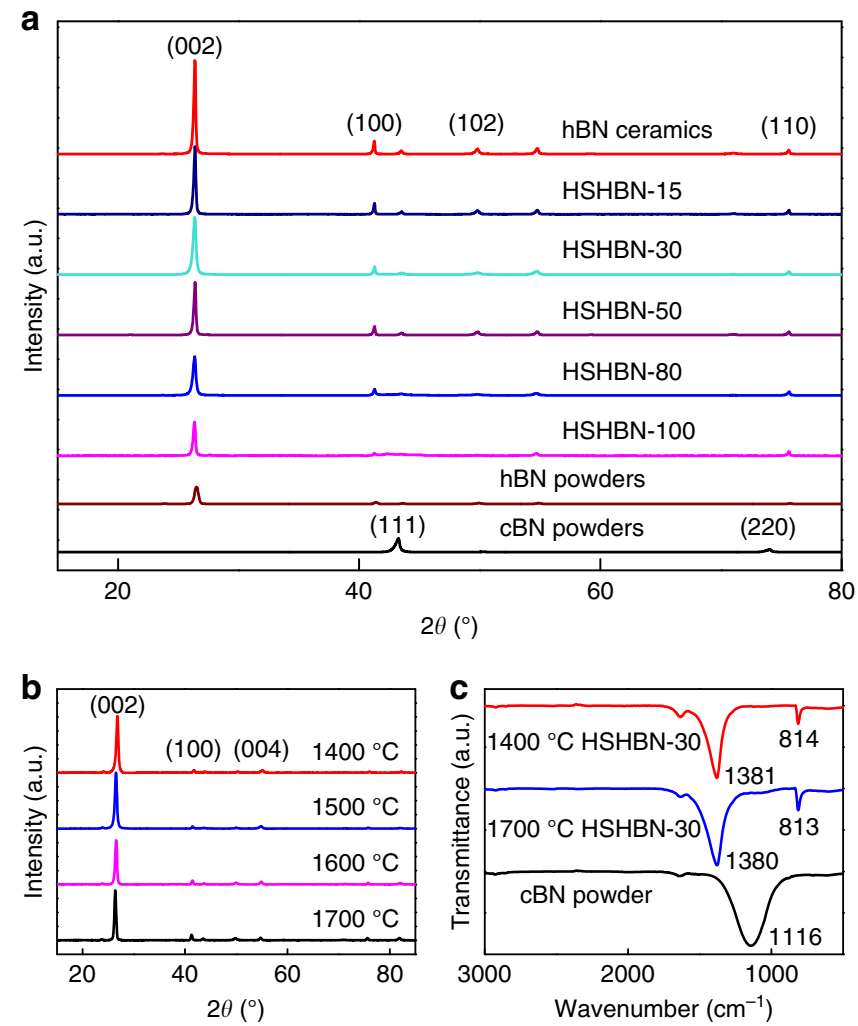

Fig. 2 Characterization of phase evolution in the as-prepared samples. XRD patterns of the $c B N$ and $h B N$ precursor powders, pure $h B N$ ceramics and HSHBN samples sintered at $1700^{\circ} \mathrm{C}(\mathbf{a})$; XRD patterns of $\mathrm{HSHBN}-30$ with sintering temperatures of $1400^{\circ} \mathrm{C}-1700^{\circ} \mathrm{C}(\mathbf{b})$; Fourier transform infrared spectroscopy (FTIR) spectra of $\mathrm{cBN}$ powder, and HSHBN-30 samples sintered at $1400^{\circ} \mathrm{C}$ and $1700^{\circ} \mathrm{C}$ (c) continuously with increasing $\mathrm{cBN}$ addition, as the onions formed from $\mathrm{cBN}$ during sintering have an isotropic microstructure. The HSHBN-30 samples sintered at temperatures of $1400{ }^{\circ} \mathrm{C}-1700^{\circ} \mathrm{C}$ were also analysed by X-ray diffraction (Fig. 2b). The XRD patterns of all the HSHBN-30 samples sintered at different temperatures show that the $\mathrm{cBN}$ sintered at or above $1400{ }^{\circ} \mathrm{C}$ has been completely transformed to $\mathrm{BN}$ onions.

Figure $2 \mathrm{c}$ shows the room temperature FTIR spectra of $\mathrm{cBN}$ powder, 1400 and $1700{ }^{\circ} \mathrm{C}$ sintered $\mathrm{HSHBN}-30$. The spectrum of HSHBN-30 contains two strong peaks at approximately 1379 and $813 \mathrm{~cm}^{-1}$, which are assigned to $\mathrm{B}-\mathrm{N}$ stretching vibrations and $\mathrm{B}-\mathrm{N}-\mathrm{B}$ bending vibrations, respectively, as detailed by previous reports ${ }^{18,19}$. The weak peak at $1632 \mathrm{~cm}^{-1}$ is the stretching vibration peak of $\mathrm{O}-\mathrm{H}$ in $\mathrm{H}_{2} \mathrm{O}$. The $1116 \mathrm{~cm}^{-1}$ peak attributed to cBN cannot be detected ${ }^{20}$, an observation that supports the results of the XRD analysis (Fig. 2a) indicating that the $\mathrm{CBN}$ phase completely disappears during sintering. Additionally, the peak attributable to O-B-O vibrations at $490 \mathrm{~cm}^{-1}$ could not be detected (Fig. 2c), suggesting that near-zero amount of $\mathrm{B}_{2} \mathrm{O}_{3}$ is present in the HSHBNs ${ }^{17}$.

Transmission electron microscopy (TEM) micrographs of different regions of $\mathrm{HSHBN}-30$ are shown in Fig. 3. Two different morphologies are presented in Fig. 3a. One features the layered structure of hBN flakes, while the other shows the BN onions squashed by the applied pressure during SPS. The high resolution transmission electron microscopy (HRTEM) images clearly show the parallel lattice fringes of the hBN flakes and the curved lattice fringes of the concentric BN onions. The TEM observations also provide some insight into aspects of the $\mathrm{cBN}$ to $\mathrm{hBN}$ phase transformation of during sintering. The $\mathrm{BN}$ onions appear deformed, likely by the applied pressure of the sintering process, with the outer layers of the onions being squeezed and entwined together to form strong bonds between the $\mathrm{BN}$ onions and $h B N$ flakes.

The inset of Fig. 3c shows the selected area electron diffraction (SAED) pattern collected from the sample of HSHBN-30. The fuzzy and discontinuous ring diffraction patterns manifest the polycrystalline nature of the HSHBN. The rings correspond to the (002) and (100) planes of $\mathrm{hBN}$, respectively, in good agreement with the $\mathrm{XRD}$ results. These results demonstrate that $\mathrm{cBN}$ has completely transformed to $\mathrm{BN}$ onions.

Sintering mechanism. The sintering of powders is usually associated with volumetric shrinkage of the compact due to the elimination of voids between particles. To achieve a high packing density and reduce pores in the powder compact, particle size gradation is very important. Smaller particles are added to fill the voids between larger particles to obtain a high packing density. Horsfield filling theory ${ }^{21}$ addresses the relationship between the particle size distribution, volume fraction and porosity of mixed powder compacts. Based on this rule, two different $\mathrm{cBN}$ powder particle sizes (200 $\mathrm{nm}$ and $400 \mathrm{~nm}$ ) were added a ratio of 1:3 to fill the voids between $\mathrm{hBN}$ flakes to achieve a high packing density.

The relative densities of the HSHBN samples are shown in Fig. 4. The measured-relative densities of pure $\mathrm{hBN}$ and pure $\mathrm{cBN}$ sintered at $1700{ }^{\circ} \mathrm{C}$ are approximately 93 and $88 \%$, respectively. Relative density was observed to increase with increasing cBN content, reaching a maximum at $30 \mathrm{wt} \% \mathrm{cBN}$. The relative density of HSHBN-30 reached $95.5 \%$ at $1600{ }^{\circ} \mathrm{C}$, slightly higher than the highest-reported result for $\mathrm{hBN}$ ceramics, of $95.1 \%$ in a sample sintered at $2000{ }^{\circ} \mathrm{C}^{11}$. When the sintering temperature is increased to $1700^{\circ} \mathrm{C}$, the relative density of the HSHBN-30 correspondingly increases to $97.6 \%$. Supplementary Figure 2 shows the field emission scanning electron microscopy (FESEM) micrographs on polished surfaces of the samples. 

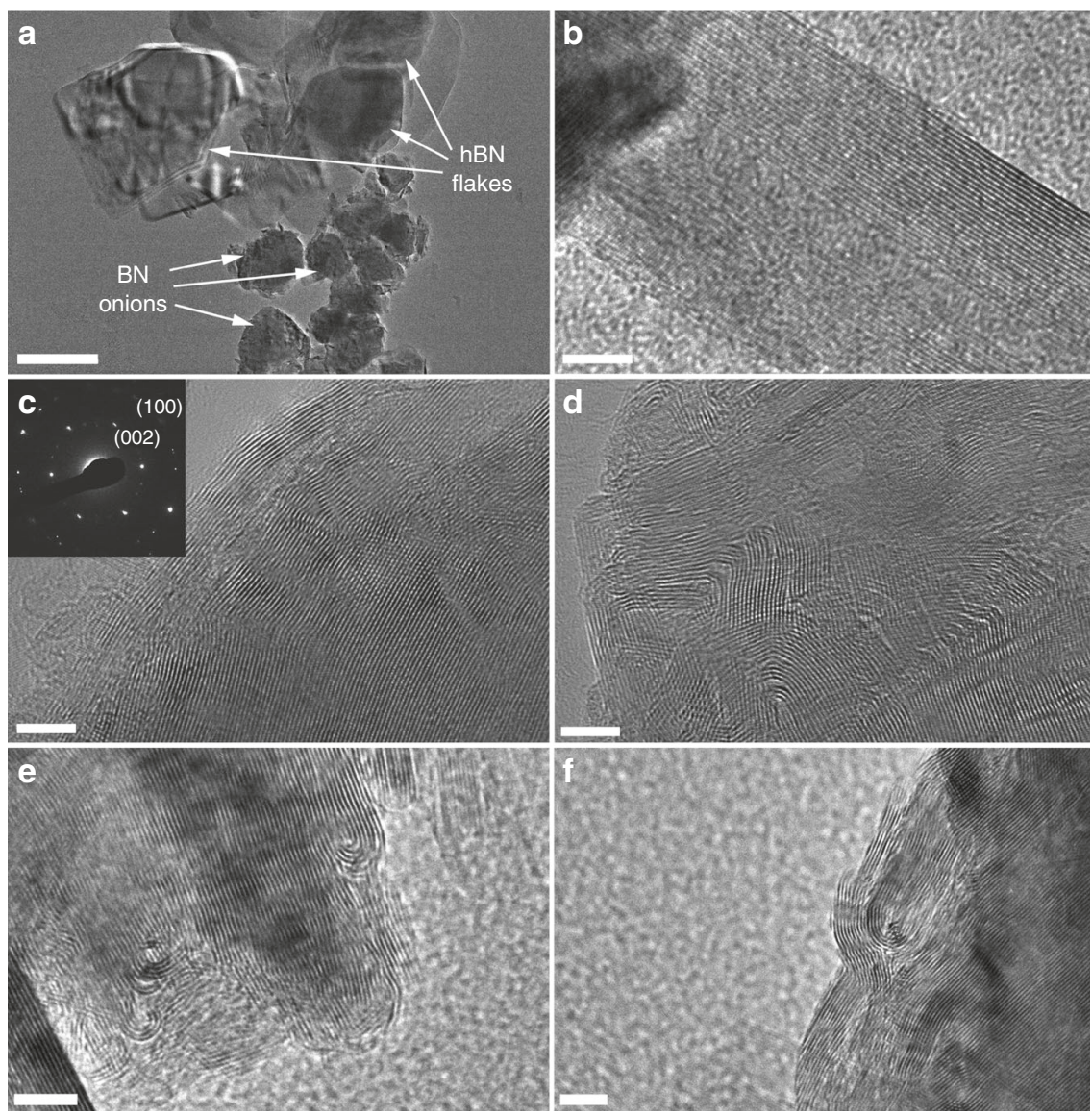

Fig. 3 TEM images of HSHBN-30 sample. TEM image of squashed BN onions and hBN flakes (a); HRTEM images of hBN flakes (b); BN onion associated SAED pattern (c), deformed and entwined BN onions (d), and the curly hBN layer shells stripped from the BN onions (e, $\mathbf{f}$ ). The scale bar is $500 \mathrm{~nm}$ in $\mathbf{a}$, and represents $5 \mathrm{~nm}$ in $\mathbf{b}-\mathbf{f}$
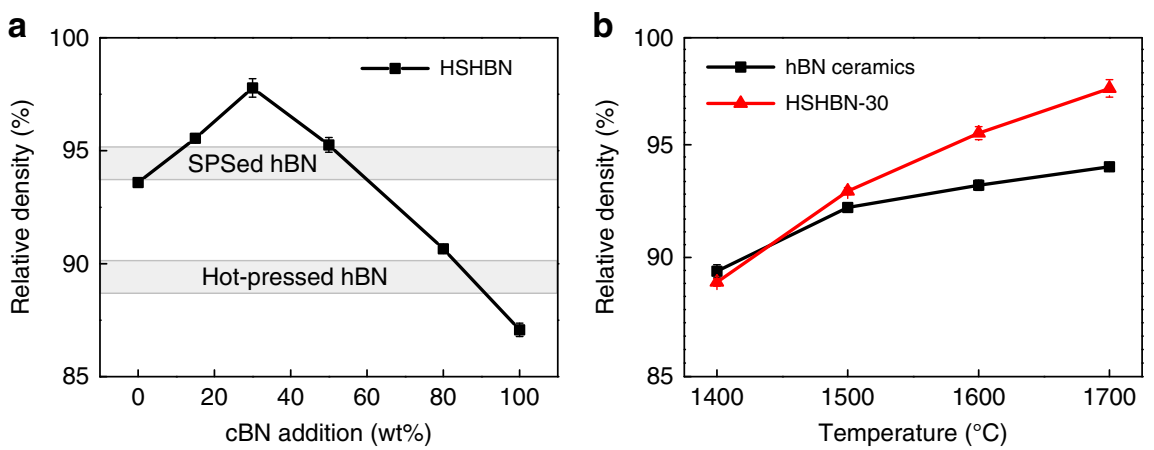

Fig. 4 Relative densities of HSHBNs and pure hBN ceramic. Relative densities of the bulk HSHBNs sintered at $1700^{\circ} \mathrm{C}$ with different cBN contents, with the highest relative densities reported from other studies shown in the shadowed areas (a), and the temperature dependence on the relative density of pure hBN ceramics and HSHBN-30 (b). All error bars represent standard deviations, and $n=5$

For traditional powder consolidation, the sintering process is composed of three stages ${ }^{22}$. The initial stage consists of particle rearrangement, followed by volumetric shrinkage. Then, particle neck growth occurs, and densification proceeds via mass transport and atom diffusion. During the third stage, pore elimination and rapid grain growth occur. During SPS, the grain growth typically taking place during the third stage is reduced by the short time interval over which the process is conducted; however, coarsening is not completely inhibited.

In the traditional phase transformation-assisted sintering of $\mathrm{TiO}_{2}^{23}$, two major driving forces contribute to the sintering. One is the enthalpy change of the anatase to rutile transformation, and the enthalpy of anatase-rutile transformation is $6.51 \mathrm{~kJ}$ $\mathrm{mol}^{-1}$. The other is the release of surface energy due to grain growth. However, in our present work, no significant grain growth is observed that reduces the surface energy. The enthalpy change $\left(\Delta_{\mathrm{tr}} H_{\mathrm{c}-\mathrm{h}}\right)$ of the $\mathrm{cBN}-\mathrm{hBN}$ phase transition was calculated according to the Kirchhoff's law. In the case of little change in pressure, $\Delta_{\mathrm{tr}} H_{\mathrm{c}-\mathrm{h}}(1673.15 \mathrm{~K})=15.4867 \mathrm{~kJ} \mathrm{~mol}^{-1}$, i.e., $15.4867 \mathrm{~kJ} \mathrm{~mol}^{-1}$ of heat is absorbed at $1400^{\circ} \mathrm{C}$ (Supplementary Note 2). It is manifested that $\mathrm{CBN}$ itself has no release of energy as a sintering driving force in the phase transformation process at $1400^{\circ} \mathrm{C}$. Therefore, other densification mechanisms must exist. 
a

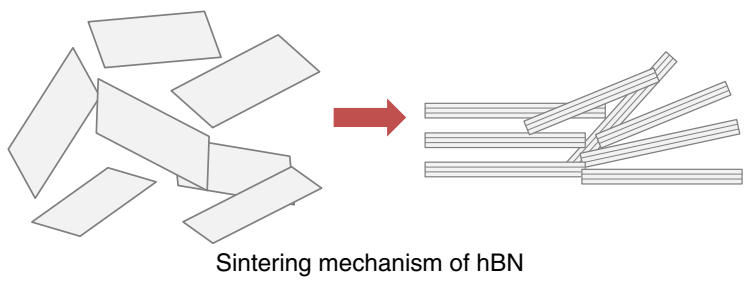

b
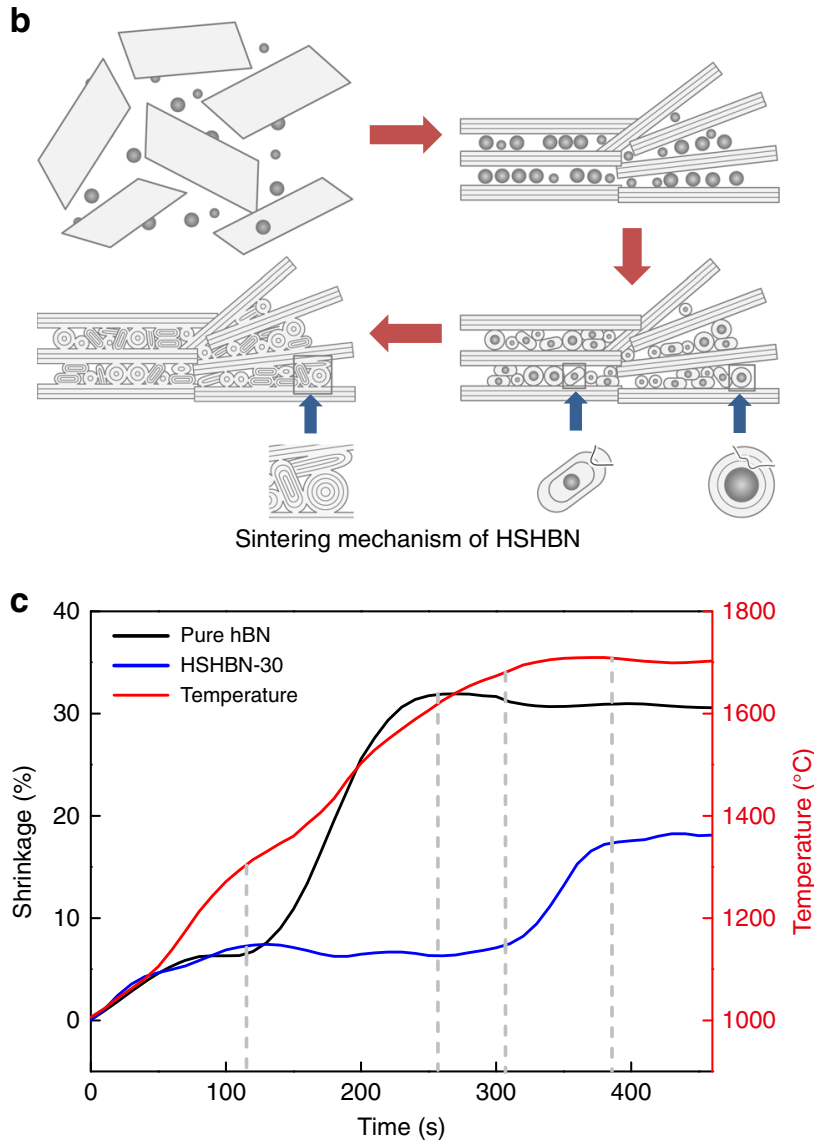

Fig. 5 Consolidation mechanisms of $h B N$ and HSHBN during SPS. Sintering mechanisms of pure hBN (a) and $\mathrm{HSHBN}(\mathbf{b})$, and sintering shrinkage curves of pure hBN and $\mathrm{HSHBN}-30$ above $1000^{\circ} \mathrm{C}$ (c)

The sintering mechanism of HSHBN is presented in Fig. 5b. The phenomena occurring in all three stages of sintering must be considered to understand the mechanism by which the HSHBN sintering process occurs. First, the hBN flakes and cBN particles are rearranged to form a denser compact, due to the effects of applied pressure. To achieve this, the smaller $\mathrm{cBN}$ particles must partially fill the voids between $\mathrm{hBN}$ flakes, thus increasing the packing density. As the temperature is ramped up to $1400^{\circ} \mathrm{C}$, the $\mathrm{cBN}$ particles gradually transform to $\mathrm{BN}$ onions. It is at this point that the self-densifying mechanism of the $\mathrm{cBN}$ begins to occur. $c B N$ has a much greater density than $\mathrm{hBN}$, and thus upon transformation of $\mathrm{cBN}$ to $\mathrm{hBN}$, a phase transition-induced volume expansion of approximately $50 \%$ occurs. Due to the geometry of the onions, the greatest stresses will occur at the outside of the particle, and thus the transformation will occur from the outside of the $\mathrm{cBN}$ particle and gradually moves inwards. During SPS, as the powders are confined in the die and due to the intensive local stresses occurring at the contact points between $\mathrm{cBN}$ particles, the $\mathrm{hBN}$ shell layers formed early in the process are essentially extruded into the pores between flakes, assisting in the densification process. Such $\mathrm{hBN}$ layer shells that have been deformed and curled under pressure are shown in Fig. 3e, f. Understandably, BN onions are to be squashed by the intense stresses to further compact densely.

With the transformation proceeding, a volume expansion associated with the phase transformation continues, and more empty space becomes occupied by the expanding $\mathrm{BN}$ onions. The outer layers of the $\mathrm{BN}$ onions also become entwined with the layers of the $\mathrm{hBN}$ flakes as they grow, forming a semi-interlocking structure.

Last but not least, during the phase transformation, the $\mathrm{B}$ and $\mathrm{N}$ atoms forming the cBN particles are very active, and the resultant rapid atomic diffusion is beneficial to the densification and elimination of pores among particles ${ }^{23,24}$. More importantly, the highly active $\mathrm{B}$ and $\mathrm{N}$ atoms create strong bonding between hBN flakes and BN onions to form a robust bulk.

Figure $5 \mathrm{c}$ shows the shrinkage curves of pure $\mathrm{hBN}$ and HSHBN-30 samples. Because of the $\mathrm{CBN}$-derived BN onions that hinder the sintering of $\mathrm{hBN}$ powder, the shrinkage of HSHBN-30 starts at $\sim 1650{ }^{\circ} \mathrm{C}$ while densification happens to the pure $\mathrm{hBN}$ sample at $\sim 1350{ }^{\circ} \mathrm{C}$. The distinct feature is the significantly smaller overall shrinkage of the denser HSHBN-30 ( 16\%) compared to that of the less denser, pure hBN $(\sim 30 \%)$, strongly demonstrating that the volumetric expansion associated with the transformation of $\mathrm{cBN}$ to $\mathrm{hBN}$ makes a major contribution to the densification of HSHBN-30.

As shown in Fig. 4a, the relative densities of the two pure samples are much lower than those of the doped ones, further substantiating the notion that the addition of $\mathrm{CBN}$ to form $\mathrm{BN}$ onions assists in the filling of the pore space between $\mathrm{hBN}$ flakes. On the one hand, the cBN particles enhance the sintering by producing a larger volume of $h B N$. On the other hand, these tiny $\mathrm{cBN}$ particles act as a second phase that hinders the sintering of $\mathrm{hBN}$ flakes. However, too many $\mathrm{BN}$ onions will form a rigid connecting network that hinders the consolidation. Thus, a balance has to be reached to produce the densest material, which is $\mathrm{HSHBN}-30$ in this case.

In summary, during consolidation, the transformation of $\mathrm{cBN}$ particles to $\mathrm{BN}$ onions plays a key role by forming an additional volume of $h B N$ that acts as a sort of glue bonding the $h B N$ flakes together, which is a spontaneous and self-densifying process.

Obviously, a temperature increase enhances the sintering of hBN flakes, which occurs both in pure and doped hBN compacts. As shown in Fig. 4b, a higher temperature enhances the sintering of HSHBN-30 more significantly than that of pure hBN ceramics. In fact, a higher temperature facilitates the deformation of BN onions that contributes to the densification by eliminates avoids among the spherical $\mathrm{BN}$ onions. For example, according to the established Coble or Nabarro-Herring diffusion mechanisms, B and $\mathrm{N}$ atoms migrate along or across a $\mathrm{BN}$ onion from the onion top under the compressive stress to the onion lateral that is under tensile stress, which strongly depends on the temperature in addition to local stresses. In contrast, when a compact of only hBN powder is sintered, atoms have to diffuse over relatively long distances to reach regions where they will fill voids.

Mechanical behaviour. To understand the mechanical behaviours of the produced HSHBN materials, compression, flexural and nanoindentation tests were performed on polished samples. For the boron nitride samples sintered at $1400^{\circ} \mathrm{C}$, because the lubricity of hBN makes it compact more easily. However, flexural tests revealed the higher density does not necessarily reflect a more advanced degree of sintering in the sample. Compressive strength measurements (Fig. 6a) performed on both the pure hBN ceramics and HSHBN-30 show an increase in strength with increasing sintering temperature. The compressive strength of the 

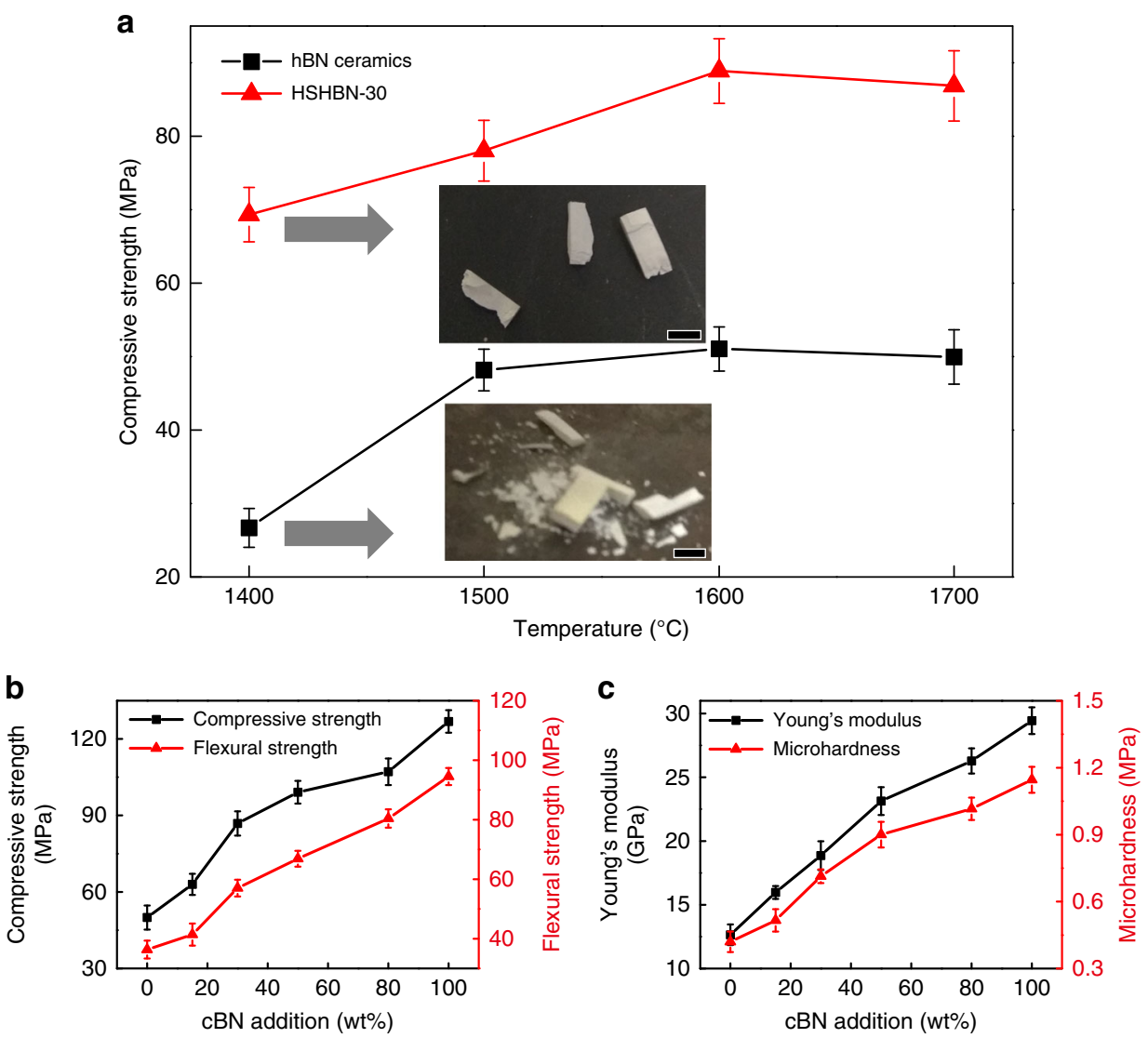

Fig. 6 Mechanical properties of HSHBN samples. Plot showing the dependence of compressive strength on sintering temperature for both the pure hBN and HSHBN-30 ceramics, and photographs show the $1400^{\circ} \mathrm{C}$-sintered samples after testing, and all scale bars represent $6 \mathrm{~mm}$ (a); compressive and flexural strength (b), Young's modulus and microhardness measurements (c) of the $1700^{\circ} \mathrm{C}$-sintered pure hBN ceramics and HSHBNs. All the error bars represent standard deviations, and $n=5$

$1400{ }^{\circ} \mathrm{C}$-sintered $\mathrm{hBN}$ ceramics is very low, and compressive strength testing of the pure hBN sample crushed the test specimen into small fragments. In contrast, the HSHBN-30 sample sintered at the same temperature only fractured into several pieces. While highly qualitative, this observation provides evidence that although the pure $\mathrm{hBN}$ has formed a relatively dense compact, this does not translate to a significant degree of sintering. Additionally, although the HSHBN sample with $30 \mathrm{wt} \%$ $\mathrm{cBN}$ had a lower relative density, mechanical testing indicate that it has undergone a more significant degree of sintering.

The nanoindentation test results are shown in Fig. 6c. A dramatic improvement in mechanical properties is apparent with the introduction of $\mathrm{cBN}$. The sample composed of $100 \% \mathrm{cBN}$ (HSHBN-100) exhibited the highest Young's modulus and microhardness of all measured samples, of 29.44 and $1.15 \mathrm{GPa}$, respectively, while the $100 \%$ hBN ceramics exhibited values of 15.97 and $0.52 \mathrm{GPa}$, respectively. These results demonstrate that the prepared HSHBNs are much stiffer and harder than the hBN ceramics consolidated by conventional means. The multiple curved layers forming the $\mathrm{BN}$ onions must possess extremely high strength to counteract the intense tensile stresses they experience, making the $\mathrm{BN}$ onions very strong, like carbon onions ${ }^{12}$. This behaviour contributes to the increased Young's modulus of the HSHBN. For conventional hBN ceramics, indentation testing may cleave the (002) crystal planes, due to the weak van der Waals forces between (002) planes, while much more energy is required to initiate fracture in the (002) layers of the BN onions in the HSHBN bulks.

To determine the relative strengths of the BN onions and hBN flakes, modelling and analysis of both morphologies were performed with ANSYS software (Fig. 7). The Young's modulus and Poisson's ratio of each layer in the two models are referenced to the values of boronitrene, which are approximately $0.85 \mathrm{TPa}$ and $0.21^{25,26}$, respectively. Uniaxial pressure of $100 \mathrm{MPa}$ was applied perpendicular to force surfaces with a radius of $15 \mathrm{~mm}$ on the models to analyse the strain and stress distribution, and the support surfaces are the entire bottom surfaces of the both models.

As shown in Fig. 7c, d, the equivalent elastic strain of $\mathrm{BN}$ onion is far less than hBN flake. What's more, the stress on the hBN flake is mainly distributed inside the body and ranges from 128.25-192.37 MPa (Fig. 7e). This onion morphology is distributed in the body evenly, and only experiences stresses of 30.71-81.07 MPa (Fig. 7f) inside the onion, approximately onethird of that in a flake. Here, we use a bigger size model to simplify the calculation, but the obtained the ratio and distribution of stresses remains and are reliable compared to the actual $\mathrm{BN}$ onion and hBN flake because the onion and flake are sufficiently large, and continuum mechanics apply. Therefore, $\mathrm{hBN}$ flakes are more susceptible than BN onions (although deformed) to damage because of the huge stress.

Due to the morphology of the BN onion being composed of multiple curved $\mathrm{BN}$ layers, the compressive strength in the direction parallel to the plane and flexural strength in the perpendicular direction increase significantly with the cBN addition, as shown in Fig. 6b. The weak interlayer van der Waals forces facilitate easy cleavage between the hBN layers, leading to the low strength of $\mathrm{hBN}$ ceramics consolidated by traditional mean. In our research, the compressive and flexural strengths of 
a

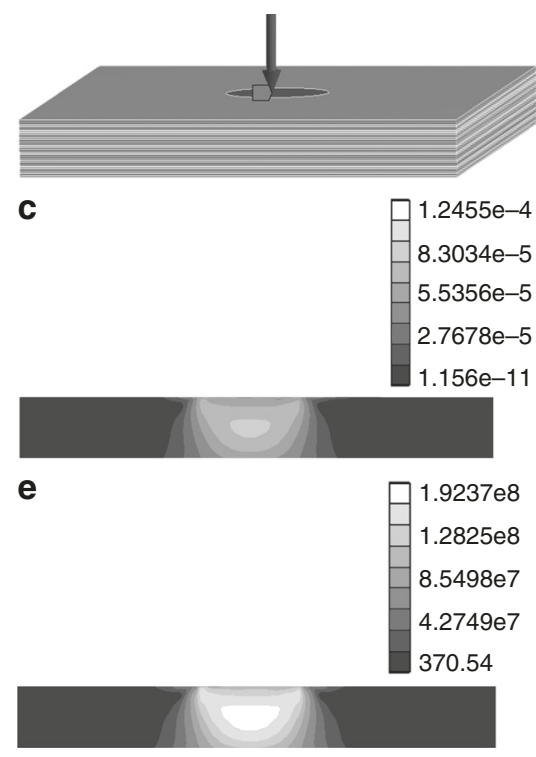

b

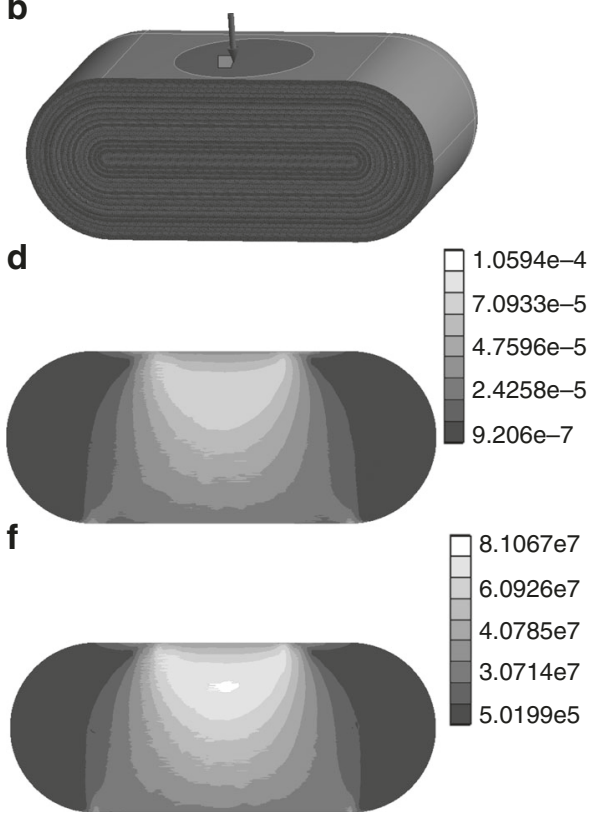

Fig. 7 Models showing the strain and stress distributions on the hBN flake and BN onion. Models of $h B N$ flake (a) and BN onion (b); equivalent elastic strain of hBN flake (c) and BN onion (d); equivalent stress of hBN flake (e) and BN onion (f)

pure hBN ceramics are $49.96 \mathrm{MPa}$ and $36.34 \mathrm{MPa}$, respectively, confirming the previously reported results $(30-50 \mathrm{MPa}$ for flexural strength) ${ }^{10,27}$. The mechanical properties of HSHBN-30 are nearly double those of the pure $\mathrm{hBN}$ sample. The flexural strength of HSHBN-100 is $94.51 \mathrm{MPa}$, approximately 3 times that of pure $\mathrm{hBN}$ ceramics. The onion morphology ensures an intrinsically higher strength relative to layered $\mathrm{hBN}$ because it isn't prone to the easy cleavage that occurs in the latter material. Furthermore, some of the outer layers of the $\mathrm{BN}$ onions are observed to be entwined with the layers of the hBN flakes, forming an interlocking structure where the onions serve as a sort of binder.

Griffith's theory of fracture for brittle materials states that the relationship of the fracture strength $\left(\sigma_{\mathrm{c}}\right)$ with the elastic modulus $(E)$, fracture surface energy $(\gamma)$, and crack size $(c)$ is described by the relation ${ }^{28}$ :

$$
\sigma_{\mathrm{c}}=\sqrt{\frac{2 E \gamma}{\pi c}}
$$

In this work, as grain growth is considered to be minimal, the enhanced bending strength of the HSHBN is primarily attributed to the effects of increased elastic modulus (Fig. 6c). Obviously, the fracture surface energy, which refers to the energy consumed to form a new surface per unit area of the material, is larger in the case of HSHBN than in pure hBN ceramics, because the fracture surface energy of curved planes of the onions are larger than the flat planes of the hBN flakes. Additionally, if the size of the $\mathrm{BN}$ particles is viewed as an intrinsic flaw size equal to the crack length $c$, which is approximately $500 \mathrm{~nm}$ for the BN onions and $\sim 1-2 \mu \mathrm{m}$ for the hBN flakes in the HSHBN bulks, a higher strength would be expected with an increasing volume fraction of onions, as the average flaw size would be significantly decreased. For the less dense HSHBNs with a high content of BN onions, as shown in Fig.6, the decrease in density does not deteriorate the mechanical properties. This demonstrates the ultra-strong innate character of the $\mathrm{BN}$ onions.
Figure 8 shows FESEM micrographs of the fracture surfaces of different HSHBN bulks after being fractured in bending. Compared to the pure hBN ceramics (Fig. 8a), the fracture surface of HSHBN reveals regions of both the layered structure characteristic of hBN, and the squashed morphology of the $\mathrm{BN}$ onions (Fig. 8e, f), with the onions being distributed between hBN flakes. It can be clearly observed that as the starting $\mathrm{cBN}$ content increases, more $\mathrm{BN}$ onions are present in the end ceramics and the preferential arrangement of the hBN flakes gradually decreases due to the onion particles preventing both the alignment and grain growth of the flakes during sintering.

\section{Discussion}

In summary, we have pioneered a new route, to consolidate boron nitride that we call a self-densifying mechanism, which result in a new family of high strength bulk $\mathrm{hBN}$ materials at low temperatures using $\mathrm{BN}$ onions produced in situ by the addition of cBN powders, which serve as both a sintering aid and reinforcement phase. $\mathrm{cBN}$ particles transformed into $\mathrm{BN}$ onions during sintering at $1700^{\circ} \mathrm{C}$ for $5 \mathrm{~min}$ with an increase in volume that served to fill the voids between larger $\mathrm{hBN}$ flakes, to produce dense bulk hBN materials with an ultra-high relative density of $97.6 \%$. The as-prepared whole-BN bulks have a microstructure with $\mathrm{BN}$ onions distributed among hBN flakes, which bestows these materials with superior mechanical properties compared to pure hBN ceramics. This material design and processing methodology may be important in many other material systems. Preliminary results of thermal conductivity and dielectric properties of the as-prepared samples are consistent with those in previous reports ${ }^{5,29,30}$ (Supplementary Note 5).

\section{Methods}

Sample preparation. hBN powder $(99.9 \%, 1-2 \mu \mathrm{m}$, Macklin Biochemical Co., Ltd., China) and two types of cBN powders $(99.5 \%$, average particle size of $200 \mathrm{~nm}$ and 400 nm, Funik Ultrahard Material Co., Ltd., China) were used as raw materials. Prior to use, the powders were treated for $10 \mathrm{~h}$ in a $5 \mathrm{wt} \% \mathrm{HCl}$ solution to remove $\mathrm{B}_{2} \mathrm{O}_{3}$ and other impurities. The different powder compositions were mixed in the proportions shown in Table 2 in absolute ethanol in a beaker by ultrasonic agitation for $30 \mathrm{~min}$, and then subsequently dried by heating under stirring for $2 \mathrm{~h}$. 

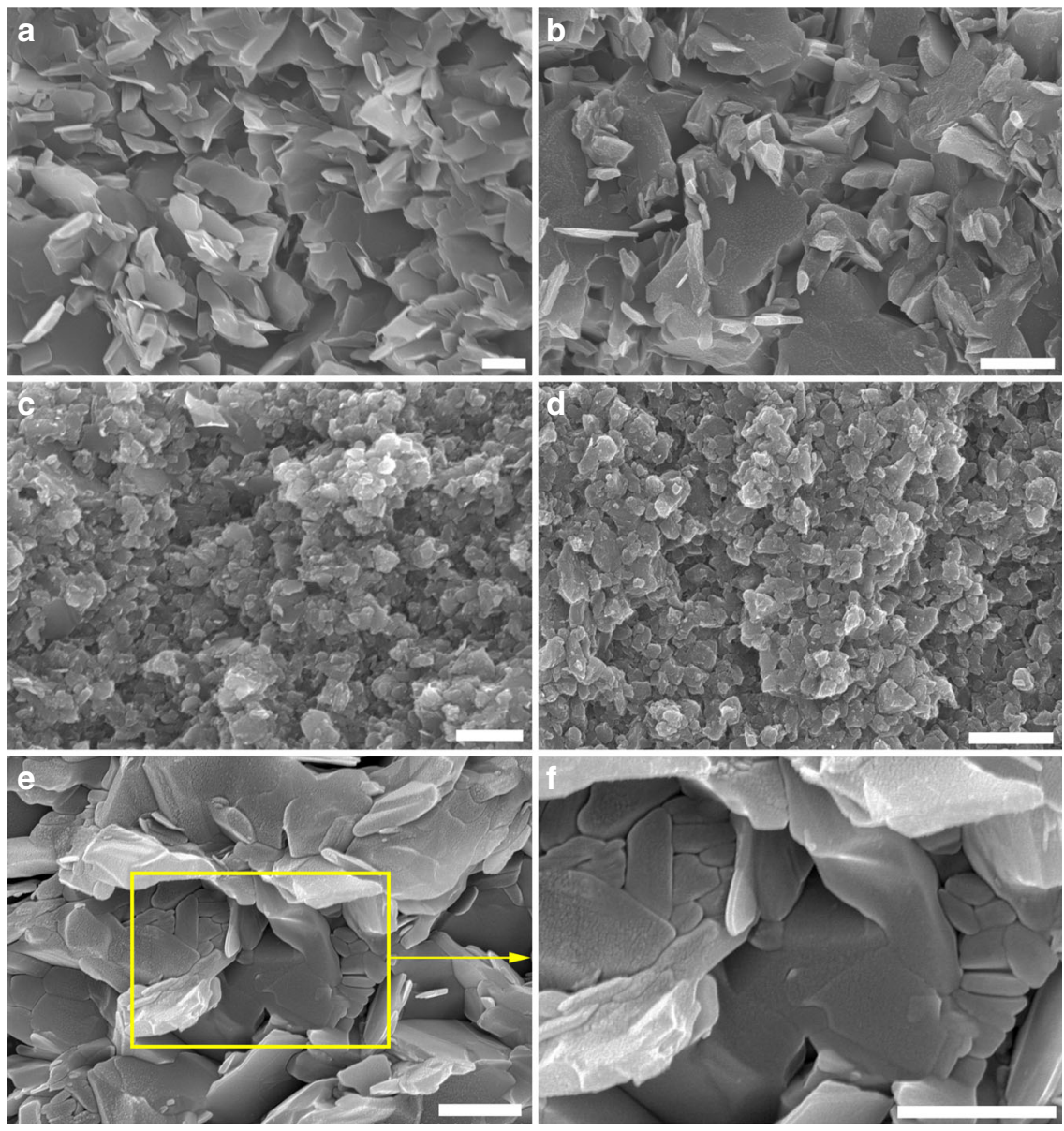

Fig. 8 FESEM micrographs of the as-prepared samples. The fracture surfaces of pure hBN ceramics (a), HSHBN-30 (b), HSHBN-80 (c) and HSHBN-100 (d); squashed BN onions in HSHBN-30 (e, f). All scale bars represent $1 \mu \mathrm{m}$

The product was then placed in an oven at $70^{\circ} \mathrm{C}$ for $10 \mathrm{~h}$ to evaporate residual solvent, and then sieved through a 120 mesh screen.

The obtained mixtures were subsequently hot pressed at $1700^{\circ} \mathrm{C}$ under an applied pressure of $80 \mathrm{MPa}$ on an SPS apparatus (Dr. Sinter 2040, Sumitomo Coal Co. Ltd., Japan), while HSHBN-30 and pure hBN ceramics were also consolidated at temperatures of $1400^{\circ} \mathrm{C}, 1500^{\circ} \mathrm{C}$ and $1600^{\circ} \mathrm{C}$ for $5 \mathrm{~min}$, at a heating rate of $150^{\circ} \mathrm{C} \min ^{-1}$.

Characterization. The sintering shrinkage curves were derived from the curves of the pressure head displacement vs time/temperature from $1000^{\circ} \mathrm{C}$ upwards, where the thermal expansion of graphite dies and samples were taken into consideration ${ }^{31}$

The Archimedes' principle density measurements were employed to determine the relative densities of all samples. The phase composition of all samples was determined using XRD (Bruker D8 Advance) with Cu-Ka radiation with a step size of $0.02^{\circ} 2 \theta$ over a scanning range of $15-85^{\circ} 2 \theta$. Microstructural characterization was performed using FESEM (Hitachi S-4800) and HRTEM (JEOL 200CX) at an accelerating voltage of $200 \mathrm{kV}$.

FTIR spectra were recorded on a Bruker TENSOR27 spectrometer with sample material embedded in $\mathrm{KBr}$ disks. Grind the samples thoroughly with an agate mortar. Transfer weighed amounts of sample powder (particle size $<10 \mu \mathrm{m}$ ) approximate $1 \mathrm{mg}$, and $\mathrm{KBr}(\mathrm{GR})$ dry powder approximate $200 \mathrm{mg}$. The two powders were mixed evenly and ground thoroughly while baked with an infrared heat lamp. Transfer the ground mixture into a mold with $10 \mathrm{~mm}$ inner diameter and pressurize to $10 \mathrm{MPa}$, then remove the pressed translucent disk. The spectrometer runs the background channel without a sample, then puts the disk and runs the sample channel. The scanning range is $3000-400 \mathrm{~cm}^{-1}$.

Mechanical performance test. Nanoindentation testing was carried out on a Bruker UMT TriboLab nanoindentation device equipped with a Berkovich pyramidal indenter. The three-point bending strength was measured on a universal testing machine (UTM, AGS-10KNG), and a crosshead speed of $0.1 \mathrm{~mm} \mathrm{~min}^{-1}$.

The models of the hBN flake and BN onion were built by SolidWorks software (Supplementary Note 3 ). The equivalent elastic strain and equivalent stress analyses of the models were carried out using ANSYS software.

\section{Data availability}

The data that support the findings of this study are available from the corresponding authors upon reasonable request.

Received: 25 September 2018 Accepted: 16 January 2019 Published online: 20 February 2019

\section{References}

1. Lipp, A., Schwetz, K. A. \& Hunold, K. Hexagonal boron nitride: fabrication, properties and applications. J. Eur. Ceram. Soc. 5, 3-9 (1989).

2. Eichler, J. \& Lesniak, C. Boron nitride (BN) and BN composites for hightemperature applications. J. Eur. Ceram. Soc. 28, 1105-1109 (2008).

3. Weng, Q., Wang, X., Wang, X., Bando, Y. \& Golberg, D. Functionalized hexagonal boron nitride nanomaterials: emerging properties and applications. Chem. Soc. Rev. 45, 3989-4012 (2016).

4. Sugino, T., Tai, T. \& Etou, Y. Synthesis of boron nitride film with low dielectric constant for its application to silicon ultralarge scale integrated semiconductors. Diam. Relat. Mater. 10, 1375-1379 (2001).

5. Ruh, R., Donaldson, K. Y. \& Hasselman, D. P. H. Thermal conductivity of boron carbide-boron nitride composites. J. Am. Ceram. Soc. 75, 2887-2890 (1992).

6. Alem, N. et al. Atomically thin hexagonal boron nitride probed by ultrahigh-resolution transmission electron microscopy. Phys. Rev. B 80, 155425 (2009).

7. Duan, X. et al. Anisotropic mechanical properties and fracture mechanisms of textured h-BN composite ceramics. Mater. Sci. Eng. A 607, 38-43 (2014).

8. Hagio, T., Kobayashi, K., Yoshida, H., Yasunaga, H. \& Nishikawa, H. Sintering of the mechanochemically activated powders of hexagonal boron nitride. $J$. Am. Ceram. Soc. 72, 1482-1484 (1989).

9. Hagio, T. \& Yoshida, H. Sintering and crystallization of ground hexagonal boron nitride powders. J. Mater. Sci. Lett. 13, 653-655 (1994). 
10. Wang, T. B., Jin, C. C., Yang, J., Hu, C. F. \& Qiu, T. Physical and mechanical properties of hexagonal boron nitride ceramic fabricated by pressureless sintering without additive. Adv. Appl. Ceram. 114, 273-276 (2015).

11. Zhang, J., Tu, R. \& Goto, T. Preparation of Ni-precipitated hBN powder by rotary chemical vapor deposition and its consolidation by spark plasma sintering. J. Alloy. Compd. 502, 371-375 (2010).

12. Ran, J. et al. A new family of carbon materials with exceptional mechanical properties. Appl. Phys. A 124, 262 (2018).

13. Vel, L., Demazeau, G. \& Etourneau, J. Cubic boron nitride: synthesis, physicochemical properties and applications. Mater. Sci. Eng. B 10, 149-164 (1991).

14. Solozhenko, V., Turkevich, V. \& Holzapfel, W. Refined phase diagram of boron nitride. J. Phys. Chem. B 103, 2903-2905 (1999).

15. Kern, G., Kresse, G. \& Hafner, J. Ab initio calculation of the lattice dynamics and phase diagram of boron nitride. Phys. Rev. B 59, 8551-8559 (1999).

16. Banhart, F., Zwanger, M. \& Muhr, H.-J. The formation of curled concentricshell clusters in boron nitride under electron irradiation. Chem. Phys. Lett. 231, 98-104 (1994).

17. Tang, C., Bando, Y., Huang, Y., Zhi, C. \& Golberg, D. Synthetic Routes and Formation Mechanisms of Spherical Boron Nitride Nanoparticles. Adv. Funct. Mater. 18, 3653-3661 (2008).

18. Cholet, V., Vandenbulcke, L., Rouan, J. P., Baillif, P. \& Erre, R. Characterization of boron nitride films deposited from $\mathrm{BCl} 3-\mathrm{NH} 3-\mathrm{H} 2$ mixtures in chemical vapour infiltration conditions. J. Mater. Sci. 29, 1417-1435 (1994).

19. Sahu, S. et al. Formation of boron nitride thin films on $\beta$-Si3N4 whiskers and $\alpha$-SiC platelets by dip-coating. J. Eur. Ceram. Soc. 18, 1037-1043 (1998).

20. Mirkarimi, P., McCarty, K. \& Medlin, D. Review of advances in cubic boron nitride film synthesis. Mater. Sci. Eng. R. Rep. 21, 47-100 (1997).

21. Tao, Z. \& Zheng, S. Powder Technology and Equipment (Chem. Ind. Press, Beijing, 2010).

22. Jonas, S., Koleżyński, A., Lis, J., Stoch, P. \& Tkacz-Śmiech, K. Model Studies of Microstructure Changes in Sintering of Ceramics. Solid State Phenom. 147-149, 890-895 (2009).

23. Kumar, K. et al. Densification of nanostructured titania assisted by a phase transformation. Nature 358, 48-51 (1992).

24. Guillon, O. et al. Field-Assisted Sintering Technology/Spark Plasma Sintering: Mechanisms, Materials, and Technology Developments. Adv. Eng. Mater. 16, 830-849 (2014).

25. Bosak, A. et al. Elasticity of hexagonal boron nitride: Inelastic $\mathrm{x}$-ray scattering measurements. Phys. Rev. B 73, 041402 (2006).

26. Andrew, R., Mapasha, R., Ukpong, A. \& Chetty, N. Mechanical properties of graphene and boronitrene. Phys. Rev. B 85, 125428 (2012).

27. Xue, J., Liu, J., Xie, B. \& Zhang, G. Pressure-induced preferential grain growth, texture development and anisotropic properties of hot pressed hexagonal boron nitride ceramics. Scr. Mater. 65, 966-969 (2011).

28. Griffith, A. The phenomena of rupture and flow in solids. Philos. Trans. R. Soc. A Math. Phys. Eng. Sci. 221, 163-198 (1921).

29. Paine, R. \& Narula, C. Synthetic routes to boron nitride. Chem. Rev. 90, 73-91 (1990).

30. Huang, X. et al. Polyhedral oligosilsesquioxane-modified boron nitride nanotube based epoxy nanocomposites: an ideal dielectric material with high thermal conductivity. Adv. Funct. Mater. 23, 1824-1831 (2013).

31. Liu, J., Shen, Z., Nygren, M., Su, B. \& Button, T. W. Spark plasma sintering behavior of nano-sized $(\mathrm{Ba}, \mathrm{Sr}) \mathrm{TiO}_{3}$ powders: Determination of sintering parameters yielding nanostructured ceramics. J. Am. Ceram. Soc. 89, 2689-2694 (2006).
32. Steinborn, C. et al. Correlation between microstructure and electrical resistivity of hexagonal boron nitride ceramics. J. Eur. Ceram. Soc. 33, 1225-1235 (2013)

33. Xu, Y., Ma, T., Wang, X., Jiang, Y. \& Yan, M. High temperature oxidation resistance of hot-pressed h-BN/ZrO2 composites. Ceram. Int. 40, 11171-11176 (2014).

34. Duan, X. et al. Effect of sintering pressure on the texture of hot-press sintered hexagonal boron nitride composite ceramics. Scr. Mater. 68, 104-107 (2013).

35. Trice, R. W. \& Halloran, J. W. Investigation of the physical and mechanical properties of hot-pressed boron nitride/oxide ceramic composites. J. Am. Ceram. Soc. 82, 2563-2565 (1999).

\section{Acknowledgements}

This work was supported by the National Key R\&D Program of China under Grant No. 2017YFB0703201 and Natural Science Foundation of China (No.51432004 and 51672041). The authors would like to thank the State Key Laboratory of Marine Resource Utilization in South China Sea for the funding support (2016011).

\section{Author contributions}

J.L. conceived the idea. H.T.Y. designed and performed the experiments and analyzed the results. H.F., Y.C., L.W. and W.J. contributed to the sample preparation and characterization. H.Y. performed the modeling by ANSYS software. J.L., L.W. and Y.W. explored the fabrication mechanisms. H.T.Y. wrote the manuscript with J.L., L.W. and Y.W. All authors contributed to the manuscript.

\section{Additional information}

Supplementary Information accompanies this paper at https://doi.org/10.1038/s41467019-08580-9.

Competing interests: The authors declare no competing interests.

Reprints and permission information is available online at http://npg.nature.com/ reprintsandpermissions/

Journal peer review information: Nature Communications thanks Takashi Goto and the other anonymous reviewer(s) for their contribution to the peer review of this work. Peer reviewer reports are available.

Publisher's note: Springer Nature remains neutral with regard to jurisdictional claims in published maps and institutional affiliations.

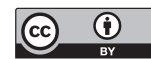

Open Access This article is licensed under a Creative Commons Attribution 4.0 International License, which permits use, sharing, adaptation, distribution and reproduction in any medium or format, as long as you give appropriate credit to the original author(s) and the source, provide a link to the Creative Commons license, and indicate if changes were made. The images or other third party material in this article are included in the article's Creative Commons license, unless indicated otherwise in a credit line to the material. If material is not included in the article's Creative Commons license and your intended use is not permitted by statutory regulation or exceeds the permitted use, you will need to obtain permission directly from the copyright holder. To view a copy of this license, visit http://creativecommons.org/ licenses/by/4.0/.

(C) The Author(s) 2019 